\title{
Spatiotemporal Relationships Between Disease Development and Airborne Inoculum in Unmanaged and Managed Botrytis Leaf Blight Epidemics
}

\author{
O. Carisse, S. Savary, and L. Willocquet
}

First author: Agriculture and Agri-Food Canada, Horticultural Research Centre, 430 Gouin Blvd., Saint-Jean-sur-Richelieu, Québec, Canada, J3B 3E6; and second and third authors: INRA, UMR Santé Végétale, BP81, 33883 Villenave d'Ornon cedex, France. Accepted for publication 17 August 2007.

\begin{abstract}
Carisse, O., Savary, S., and Willocquet, L. 2008. Spatiotemporal relationships between disease development and airborne inoculum in unmanaged and managed Botrytis leaf blight epidemics. Phytopathology 98:38-44.

Comparatively little quantitative information is available on both the spatial and temporal relationships that develop between airborne inoculum and disease intensity during the course of aerially spread epidemics. Botrytis leaf blight and Botrytis squamosa airborne inoculum were analyzed over space and time during 2 years (2002 and 2004) in a nonprotected experimental field, using a $6 \times 8$ lattice of quadrats of $10 \times$ $10 \mathrm{~m}$ each. A similar experiment was conducted in 2004 and 2006 in a commercial field managed for Botrytis leaf blight using a $5 \times 5$ lattice of quadrats of $25 \times 25 \mathrm{~m}$ each. Each quadrat was monitored weekly for lesion density (LD) and aerial conidium concentration (ACC). The adjustment of the Taylor's power law showed that heterogeneity in both LD and ACC generally increased with increasing mean. Unmanaged epidemics were characterized in either year, with aggregation indices derived from SADIE (Spatial Analysis by Distance Indices). For LD, the aggregation indices suggested a random pattern of disease early in the season,

dates in 2004. In both years and for both variables, positive trends in partial autocorrelation were observed mainly for a spatial lag of 1 . In 2002, the overall pattern of partial autocorrelations over sampling dates was similar for LD and ACC with no significant partial autocorrelation during the first part of the epidemic, followed by a period with significant positive autocorrelation, and again no autocorrelation on the last three sampling dates. In 2004, there was no significant positive autocorrelation for LD at most sampling dates while for ACC, there was a fluctuation between significant and non-significant positive correlation over sampling dates. There was a significant spatial correlation between ACC at given date $\left(t_{i}\right)$ and LD 1 week later $\left(t_{i}+1\right)$ on most sampling dates in both 2002 and 2004 for the unmanaged and managed sites. It was concluded that LD and ACC were not aggregated in the early stage of epidemics, when both disease intensity and airborne conidia concentration were low. This was supported by the analysis of LD and ACC from a commercial field, where managed levels of disease were low, and where no aggregation of both variables was detected. It was further concluded that a reliable monitoring of airborne inoculum for management of Botrytis leaf blight is achievable in managed fields using few spore samplers per field.
\end{abstract} followed by an aggregated pattern in the second part of the epidemic. The index of aggregation for ACC in 2002 was significantly greater than 1 at only one date, while it was significantly greater than 1 at most sampling
Additional keywords: aerobiology, disease management, spatial pattern, spore trapping, tactical decision.
Understanding the nature of the relationships between airborne inoculum and disease development is essential to the understanding of foliar fungal disease epidemic development. Since the classical work of Gregory (16), there has been substantial progress in the knowledge on dispersal of plant pathogen fungal spores and on spread of the disease they cause $(8,15,39,43)$. However, aerobiology has particularly focused on the analysis of long range spore dispersal, dispersal gradients, and temporal dynamics of airborne inoculum. Quantification of airborne inoculum has seldom been used per se for disease management purposes $(6,9,27)$. Understanding of plant disease development in time and in space is needed to develop management strategies. Botanical epidemiologists at first studied the temporal dynamics of plant diseases (34) and this knowledge led to the development of several forecasting systems and hence, to better disease management (18). Recently, several authors have explored the spatial and spatiotemporal structure of epidemics $(17,20,26)$. However, most of these studies focused on the spatial dynamics of disease expression (symptoms). For airborne inoculum, analysis of spore dispersal mechanisms, spore and disease gradient, and long range spore dispersal dominate the litera-

Corresponding author: O. Carisse; E-mail address: carisseo@agr.gc.ca

doi:10.1094/PHYTO-98-1-0038

(c) 2008 The American Phytopathological Society ture (21). At the field scale, spatial analyses have primarily concentrated on soilborne inoculum, with few exceptions $(3,10,27)$.

There is a demand for innovative disease management practices involving new monitoring tools, including quantification of airborne inoculum (9). However, quantification of airborne inoculum as a management tool has been disregarded until recently, because of the difficulty in measuring airborne fungal spores and the lack of knowledge on the relationships between airborne inoculum and disease development. As a result of advances in molecular biology it is now possible to quantify fungal spores from collecting surfaces of spore samplers (7). For many aerial plant diseases, our understanding of the linkage between the spatiotemporal dynamics of airborne inoculum and disease development at the field scale is limited. The long term goal of this study was to develop knowledge on spatial patterns of airborne inoculum, which could be incorporated into risk models for managing aerial plant diseases $(9,27)$.

Botrytis leaf blight, caused by Botrytis squamosa (Walker), is a major concern to onion producers in various parts of the world $(19,28,31,35)$. In the organic soils of eastern Canada, New York, and Michigan, Botrytis leaf blight is an endemic disease and severe epidemics can develop during warm and moist summers, causing reductions in bulb size and consequent yield losses $(1,5)$. $B$. squamosa overwinters as sclerotia produced on crop residues, cull piles, mother bulbs, or on the soil surface $(13,14)$. In the spring, these sclerotia are primary sources of inoculum as they 
germinate and produce conidia that are wind-dispersed $(13,14)$. Under favorable weather conditions, these conidia can infect onion leaves causing lesions and maceration of leaf tissue, resulting in leaf dieback and blighting (2). Secondary spread of the disease is caused by airborne conidia produced on necrotic tissues $(30,32)$. Sanitation and crop rotation are key elements in management of Botrytis leaf blight. However, when onions are produced in highly specialized farms, as is the case in eastern Canada, long-term crop rotation is not always economically feasible, and management of Botrytis leaf blight is mainly achieved with fungicides. In eastern Canada, management typically involves 6 to 10 fungicide treatments per season, depending on weather and disease pressure (38). Although the disease can be controlled through a calendar-based fungicide program, these fungicide sprays are not needed if environmental conditions are unfavorable for disease development, or if the availability of airborne inoculum is constrained $(9,19,28,36)$. Shoemaker and Lorbeer (28) proposed using critical disease levels (CDL) to initiate fungicide program. The CDL proposed by Shoemaker and Lorbeer (28) was adapted to the growing conditions in Canada. In Ontario, the spray threshold is set at one lesion per leaf based on observation of the three oldest green leaves ( $80 \%$ green tissue) on 50 to 100 plants across the whole field area. In the organic soil area of southwestern Montreal, fungicide programs are initiated when an average of one lesion on the oldest leaf of ten plants per field is reached. EBDC fungicides, such as Dithane are then used until an average of 10 and 3 lesions on the oldest and youngest leaves, respectively, is reached. When the disease is above this threshold, EBDC fungicides are mixed with fungicides such as Bravo (a.i., chlorothalonil) or Rovral (iprodione). Disease monitoring (28) has successfully been used as a basis for tactical management decisions, and to guide fungicide programs $(5,37)$. However, lesions of B. squamosa are small, are difficult to count, and can be easily confused with insect or soil particle damage.

Airborne inoculum plays a critical role in the development of epidemics caused by B. squamosa. Sutton et al. (32) reported a good correlation between airborne conidium concentration and severity of Botrytis leaf blight. Similarly, Vincelli and Lorbeer (38) reported that large increases in Botrytis leaf blight severity were associated with days with more than 10 conidia per $\mathrm{m}^{3}$ of air. In a recent study, Carisse et al. (9) assessed the usefulness of airborne inoculum measurements as an aid for improving Botrytis leaf blight management. The results of that study suggest that delaying the initiation of a regular fungicide spray program until a threshold of 10 to 15 conidia per $\mathrm{m}^{3}$ per hour is reached can help reduce the amount of fungicide applied by 56 to $75 \%$, compared with a conventional spray program. The adoption of such a spray decision strategy depends on the number of applications, fungicide cost, produce market value, and the cost of sampling. If conidia of B. squamosa are not uniformly distributed above the onion canopy, the use of one or of a few spore samplers in a field may not provide a reliable estimate of airborne inoculum.

This study presents results of an analysis on the spatiotemporal pattern of Botrytis leaf blight in spontaneous, unmanaged epidemics, and under commercially managed field conditions, expressed in terms of both disease and airborne inoculum. A first objective was to characterize the spatiotemporal structure of Botrytis leaf blight epidemics based on LD and ACC. A second objective was to establish the degree of spatiotemporal association between LD and ACC. A third objective was to characterize the spatial pattern of LD and ACC under commercial conditions (i.e., in a field where fungicides are applied to manage Botrytis leaf blight).

\section{MATERIALS AND METHODS}

Experimental site. The experiment was conducted at the Agriculture and Agri-Food Canada Experimental Farm at SteClotilde, Québec. The experimental plot of $60 \times 80 \mathrm{~m}$ was sown on 11 May and 30 April in 2002 and 2004, respectively, with onion (cv. Tribute) at a density of 30 seeds per meter, with a row spacing of $0.36 \mathrm{~m}$. The plots were not sprayed against Botrytis leaf blight and were treated with insecticides when necessary (11). A pre-emergence herbicide (Prowl at 7.5 liter/ha, $400 \mathrm{~g} / \mathrm{liter}$ of pendimethalin) was applied, and weeding was done four times by hand during the course of the experiments. The plot was split into 48 quadrats of $10 \times 10 \mathrm{~m}$.

Commercial site. The experiment was conducted at a commercial farm at Ste-Clotilde, Quebec. The experimental plot of $125 \times$ $125 \mathrm{~m}$ was sown on 5 May 2004 and 10 May 2006 with onion (Tribute) at a density of 30 seeds per meter with a row spacing of $0.36 \mathrm{~m}$. Insect and weed management were the same as at the experimental site. A preemergence herbicide (Prowl at 7.5 liter/ha) was applied, and weeding was done five times by hand during the course of the experiments. The spray program to manage Botrytis leaf blight was initiated when the mean number of lesions on the oldest leaf of 10 plants selected at random reached one. Subsequent fungicides were applied at 7- to 10-day intervals. When Botrytis leaf blight was at or below the threshold of 10 lesions on the oldest leaf and 3 lesions on the youngest fully expended leaf, the fungicide Dithane DG (a.i., mancozeb 75\%, Dow AgroSciences, Indianapolis, IN) was used at a rate of 2.25 to $3.25 \mathrm{~kg} / \mathrm{ha}$. When Botrytis leaf blight was above this threshold, the fungicide Rovral (a.i., iprodione, 50\%, Bayer CropScience Inc., Calgary, Alberta, Canada) at a rate of $1.5 \mathrm{~kg} / \mathrm{ha}$ mixed with the fungicide dithane was used. The plot was split into 25 quadrats of $25 \times 25 \mathrm{~m}$.

Inoculum and disease assessments. From June to August, LD and ACC were measured weekly in each quadrat of the experimental plots while LD and ACC were measured on six occasions at the commercial site. ACC was measured at the center of each quadrat using rotating-arm impaction spore samplers (Rotorod type) placed at 10 to $15 \mathrm{~cm}$ above the canopy. The height of the samplers was adjusted weekly according to onion growth and spraying equipment. The samplers ran from 10:00 a.m. to 12:00 a.m. on each sampling day. This sampling period was chosen because $B$. squamosa conidia concentrations usually reach a peak between 9:00 a.m. and 12:00 a.m. (19,30,32). In addition, sampling time was restricted to $2 \mathrm{~h}$ per sampling day to reduce the accumulation of dust on the sampling surfaces. Each sampler consisted of two vertical arms (sampling surface of $1.65 \times 20 \mathrm{~mm}$ ) separated by $83 \mathrm{~mm}$ and rotated at 2,400 rpm. Airborne particles were impacted on to the leading edges of the rotation rods. The effective sampling rate was 20.65 liters of air per minute After exposure, the number of conidia per rod was counted under a microscope at $\times 250$, and counts were transformed to conidium concentration of conidia per $\mathrm{m}^{3}$. On each sampling day, the number of lesions per leaf was counted on all leaves of five randomly chosen plants per quadrat, and disease data were expressed as LD (average number of lesions per plant).

Data analysis. All analyses were conducted separately for data collected in different years and in the unmanaged and managed plots. Data analysis was conducted in 4 steps: first, we used Taylor's power law (33) to study the relationship between observed variance and mean of both variables. Secondly, LD and ACC spatial patterns for each sampling date were classified by SADIE $(22,23)$. Thirdly, spatial autocorrelations were determined based on analysis of autocorrelograms (24). Finally, the spatial association between LD and ACC were determined based on index of association $\left(\mathrm{I}_{t}\right)$ between LD and ACC at the same sampling event $\left(t_{i}\right)$ and between LD at $t_{i+1}$ and ACC at $t_{i}$, where $i$ is the sampling event.

Variance-to-mean relationships. Taylor's power law was used to describe the relationship between mean $(M)$ and variance $(V)$ over the sampling periods separately for each variable, LD and ACC. The linear form of the power law was used to estimate the values of parameters $A$ and $b(8)$ :

$\ln (V)=\ln (A)+b \ln (M)$ 
where $V$ is the sample variance, $M$ is the sample mean, and $\ln (A)$ and $b$ are parameters. A random distribution is indicated by $\ln (A)=0$ and $b=1$, whereas values of $b>1$ indicates heterogeneity among quadrats $(20,33)$. Estimates of $\ln (A)$ and $b$ were obtained with ordinary least square regression. The significance of estimates was determined with an $F$ test. The model was evaluated based on coefficient of determination $\left(R^{2}\right)$ and mean square error (MSE) values, using the Statistical Analysis System version Windows 6.12 (SAS Institute Inc., Cary, NC).

Univariate spatial analysis. Two approaches were used to study the spatial distribution of LD and ACC. First, spatial patterns of ACC and LD were assessed using SADIE $(22,23)$. The SADIE program determines the shortest possible distance to move spatially referenced data from one location to another in order to achieve regularity. Regularity is defined as the data arrangement in which each quadrat has the same number of individuals (e.g., same values of ACC or LD). These distances are summed to provide an overall distance to regularity (observed distance to regularity), which in turn is compared with a distribution of distances calculated by randomization (simulated distance to regularity). The average of these distances gives an expected mean value of the distance to regularity, and percentiles are calculated based on the frequency distribution of the distances. The proportion of the calculated distances greater than the observed ones is used as the probability value of a one-side test of aggregation $(22,23)$. The ratio between the observed and expected distance to regularity is the index of aggregation $\left(I_{a}\right)$. When the ratio $I_{a}$ is $<1,=1$, or $>1$, the pattern of distribution is considered regular, random, or aggregated, respectively $(22,23)$. A $\chi^{2}$ test was used to determine whether $\mathrm{I}_{\mathrm{a}}$ was significantly $(P<$ 0.05 ) different from 1.

Secondly, spatial autocorrelations and partial spatial autocorrelations (24) were calculated for the unmanaged epidemics, for each sampling date and for both variables. Autocorrelograms were generated for different proximity patterns (rook, bishop, and queen). To account for the nonstationarity of the data, temporal differencing was used while calculating autocorrelations (24). A purely spatial analysis was conducted for three spatial lags and autocorrelograms were generated using the software STAUTO (24).

Spatiotemporal association between ACC and LD. The degrees of association between (i) LD and ACC at the same sampling event $\left(t_{i}\right)$, and (ii) between LD at $t_{i+1}$ and ACC at $t_{i}$ were assessed using SADIE in order to account for the spatial location of the data. SADIE generates an index of association $\left(\mathrm{I}_{t}\right)$ between two variables. When $I_{t}$ is significantly greater than 1 , the association between variables is positive $(22,23)$.

\section{RESULTS}

In unsprayed plots, Botrytis leaf blight was less severe in 2002 with a maximum of 509 lesions per plant (average of 48 quadrats) reached on 1 August (82 days after sowing) (Fig. 1). In 2004, the LD reached a maximum of 1,038 lesions per plant (average of 48 quadrats) on 30 July (91 days after sowing) (Fig. 1). Similarly, fewer conidia were trapped in 2002 with a maximum of 245 conidia per $\mathrm{m}^{3}$ on 15 August (average of 48 quadrats) compared with 1,677 conidia per $\mathrm{m}^{3}$ trapped on 4 August in 2004 (Fig. 1). For both years and both variables, no pattern of aggregation could readily be observed. Overall, from one sampling date to another, quadrats with higher values were not in the same location. At the commercial site, onions were sprayed seven and eight times during the course of the experiment in 2004 and 2006, respectively (Fig. 1). LD varied from 0.00 to 15.8 and from 0.00 to 43.0 lesions per plant (average of 48 quadrats) in 2004 and 2006, respectively (Fig. 1). Airborne conidium concentration varied from 0.00 to 16.8 and from 0.00 to 56.7 conidia per $\mathrm{m}^{3}$ (average of 48 quadrats) in 2004 and 2006, respectively (Fig. 1).

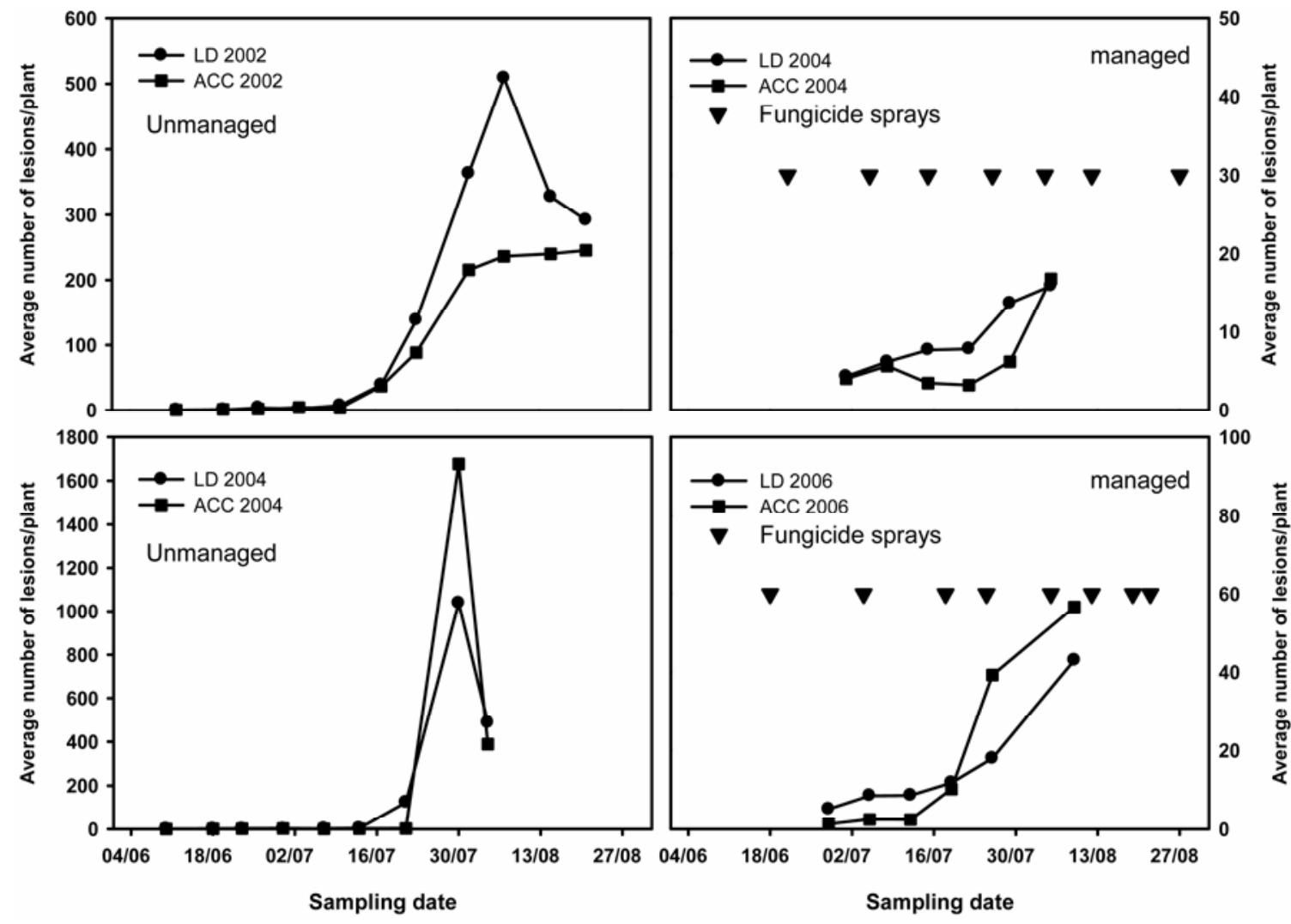

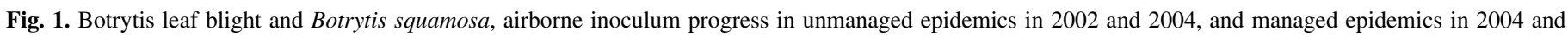
2006. Data are average values of 48 and 25 quadrats for the unmanaged and managed epidemics, respectively. 
Variance-to-mean relationships. For both unmanaged and managed epidemics of Botrytis leaf blight, there was a significant relationship $(P<0.05)$ between $\ln (V)$ and $\ln (M)$ for both years and both variables and the residual plots did not show a nonlinear relationship. For LD, the estimates of $b$ were significantly greater than $1(P<0.05)$ in $2002(b=1.677)$ but not in $2004(b=0.571)$ (Table 1). Heterogeneity thus increased with mean in 2002, but not in 2004. For ACC, the estimates of $b(b=1.700$ and 1.7601) were significantly greater than $1(P<0.05)$ in both 2002 and 2004 (Table 1). Both years, the predicted values from equation 2 were above the predicted values corresponding to a random pattern $(\ln (A)=0$ and $b=1)$ and departure from predicted values increased with increasing airborne conidia concentration, indicating that heterogeneity increased with increasing mean. For the managed epidemics, the parameter $\ln (A)$ was significantly different from 0 for LD in 2004 but not for ACC in 2004 and both LD and ACC in 2006 (Table 1). The estimate of $b$ was not significantly $(P<0.05)$ greater than 1 for LD in $2004(b=0.774)$, ACC in $2004(b=0.649)$, LD in $2006(b=1.32)$ and ACC in $2006(b=$ 0.1 .411 ) (Table 1), indicating that heterogeneity in excess of levels expected for a random pattern was apparent for either disease, or airborne inoculum levels.

Univariate spatial analysis. For the unmanaged epidemics, both variables and most sampling dates in 2002 and 2004, the index of aggregation measured by SADIE was $>1$, indicating some level of aggregation (Fig. 2). However, based on $\chi^{2}$ tests, spatial aggregation was detected $(P \leq 0.025)$ only on some sampling dates. In 2002, the index of aggregation for LD was significantly $>1$ from 17 July to 15 August with the exception of 23 July (Fig. 2) suggesting a random spatial pattern of disease early in the season followed by an aggregated distribution. Similarly, in 2004 the index of aggregation for LD was not significantly $>1$ for the first four sampling dates and then significantly $>1$ for the remaining part of the season except on the last sampling date (Fig. 2). The trend in SADIE index of aggregation of ACC was different in 2002 than in 2004 (Fig. 2). In 2002, the index of aggregation was significantly $>1$ only on 26 June. In 2004 , the index of aggregation was significantly $>1$ on all sampling dates except on 10 June and on 4 August, the first and last sampling dates, respectively, and on 7 July (Fig. 2). At the commercial site, the index of aggregation measured by SADIE was $>1$ for both variables and most sampling dates, suggesting some level of aggregation. However, based on $\chi^{2}$ tests, spatial aggregation was not significant $(P \leq 0.025)$ on all of the sampling dates with the exception of ACC on 8 August 2006 (Fig. 2).

Positive trends in partial autocorrelation were observed mainly for a spatial lag of 1 (Fig. 3) for both years and both variables at the experimental farm. The partial autocorrelations were not significant $(Z<1.96)$ in 2002 for LD from 12 June to 3 July, but positive autocorrelations were observed for the rest of the epidemic, except on 7 August (Fig. 3). The overall pattern was similar for ACC, with no significant partial autocorrelation observed from 12 June to 26 June, followed by a period with significant positive autocorrelation from 3 July to 1 August and again no autocorrelation for the last three sampling dates (Fig. 3). In 2004, there was no significant positive autocorrelation among LD values except on 21 July and 30 July. There were fluctuations between significant and nonsignificant positive correlation among ACC
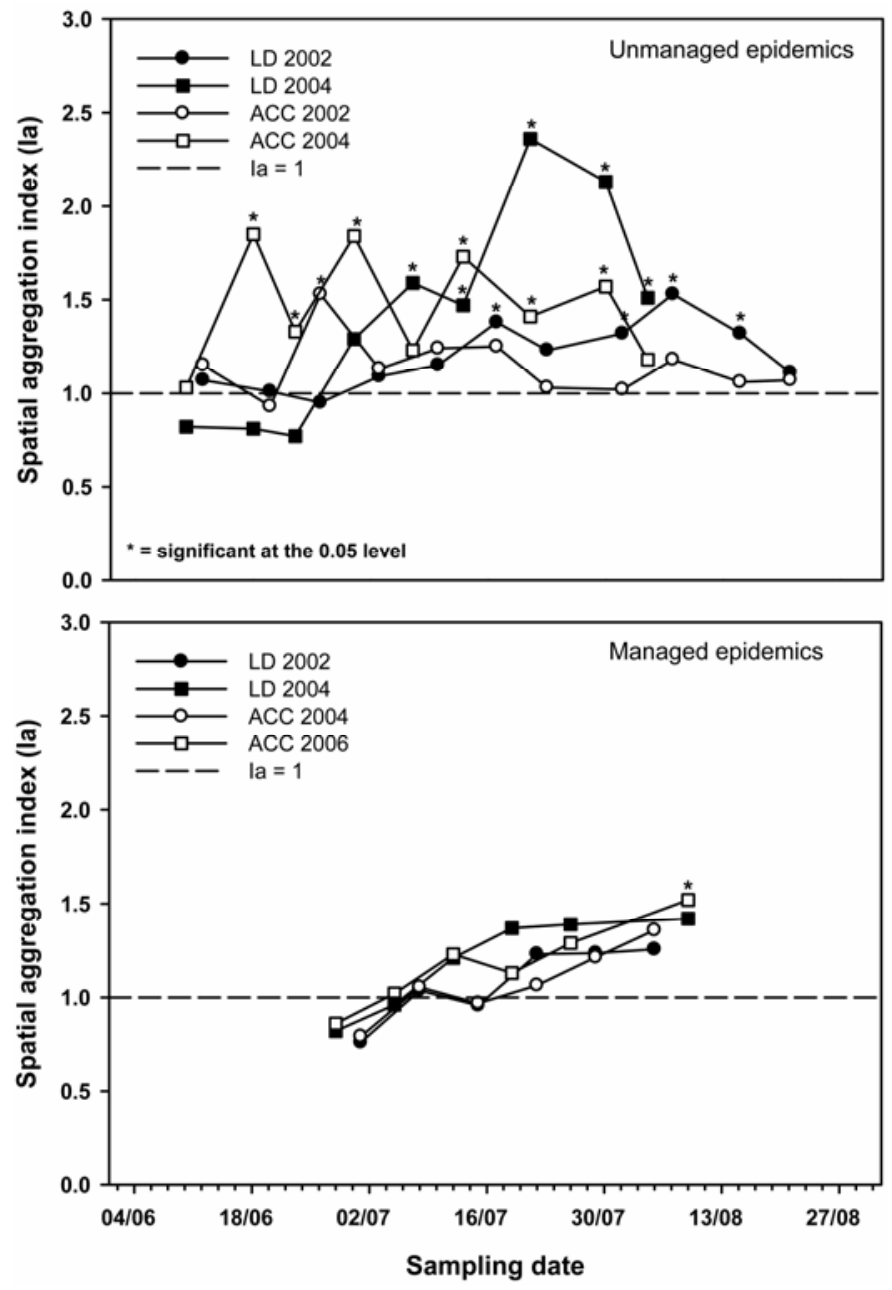

Fig. 2. Spatial aggregation index $\left(\mathrm{I}_{\mathrm{a}}\right)$ measured by spatial analysis by distance indices (SADIE) for lesion density (LD) and airborne conidia concentration (ACC) of Botrytis squamosa from unmanaged epidemics in 2002 and in 2004, and a managed epidemic in 2004 and 2006. * Indicate that probability value for $\chi^{2}$ test is $<0.05$.

TABLE 1. Results of the Taylor's power law regression analysis relating the variance and mean airborne conidia concentration (ACC) and lesion density (LD) in Botrytis squamosa

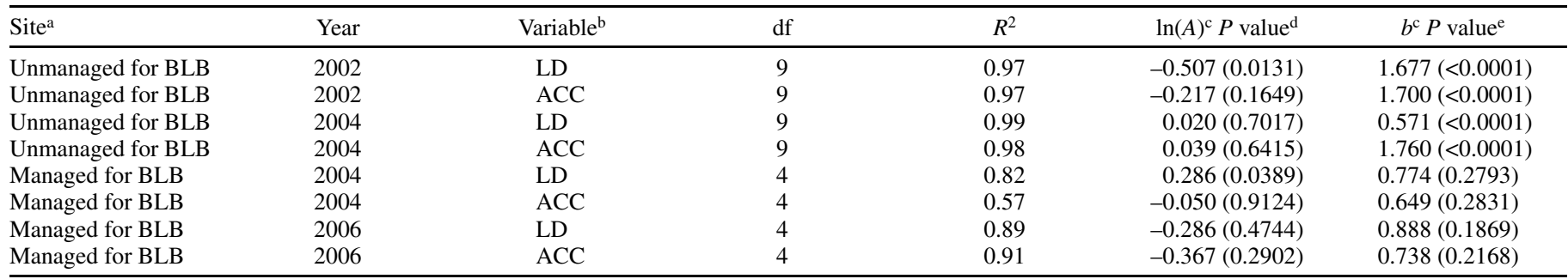

${ }^{a}$ BLB, Botrytis leaf blight.

${ }^{\mathrm{b}} \mathrm{LD}$ is the average number of lesions per plant (average over five plants per quadrat) and ACC is expressed in conidia/ $\mathrm{m}^{3}$. Means and variances were calculated from a $6 \times 8$ lattice consisting of $10 \times 10 \mathrm{~m}$ quadrats.

${ }^{c} \ln (A)$ is the estimated intercept and $b$ is the estimated slope.

d Significance level for estimated parameter different from 0.

e Significance level for estimated parameter different from 1 . 
values over sampling dates (Fig. 3). At the commercial (fungicide-protected) site, no positive trends in partial autocorrelation were observed for the spatial lags of one to three for both variables.

Spatiotemporal relationship between airborne conidia concentration and disease severity. At the unmanaged site, in 2002, spatial correlations between LD and ACC at successive dates, $t_{i}$, were not significant on most sampling dates except for 26 June, 3 July, 17 July, and 23 July (Table 2). Similarly, in 2004 spatial correlations between LD and ACC at successive dates, $\mathrm{t}_{\mathrm{i}}$, were not significant on most sampling dates, except for 18 June, 30 June, 7 July, and 13 July. However, the spatial correlation between LD at $t_{i+1}$ and ACC at $t_{i}$ was significant on most sampling dates (Table 2). In both 2004 and 2006, at the commercial (fungicide-protected) site, the spatial correlations between LD and ACC at $t_{i}$, and between LD at $t_{i+1}$ and ACC at $t_{i}$ were significant for all sampling dates (Table 2). However, the degree of correlation between LD at $t_{i+1}$ and ACC at $t_{i}$ was higher than between LD at $t_{i}$ and $\mathrm{ACC}$ at $\mathrm{t}_{\mathrm{i}}$ (Table 2).

\section{DISCUSSION}

The goal of this study was to increase our understanding of the relationships between airborne inoculum and disease development over space and time at the field scale. The spatial pattern of distribution of lesion density and airborne conidium concentration
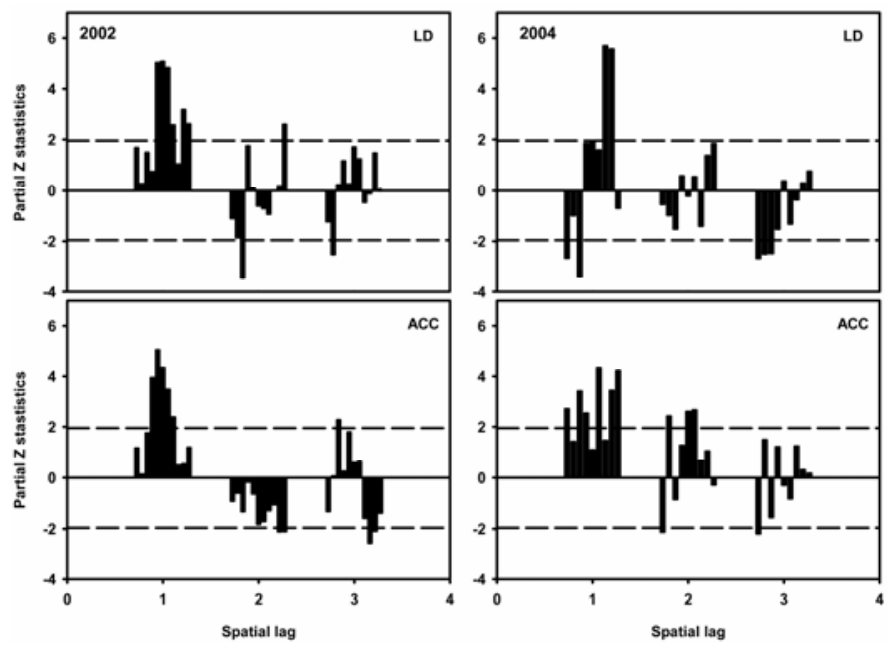

Fig. 3. Partial $Z$ statistic measured by STAUTO software as a function of spatial lag for Botrytis squamosa lesion density (LD) and airborne conidium concentration (ACC) in 2002 and in 2004. Each bar represents the $Z$ statistic for each sampling date in chronological order. of B. squamosa was studied during the course of unmanaged and managed epidemics. To our knowledge, this was the first reported analysis of the spatiotemporal distribution patterns of airborne inoculum of B. squamosa, and among the few studies linking the aerobiology of a fungal pathogen simultaneously with disease progress while accounting for spatial patterns $(4,6,10)$. Spontaneous epidemics of Botrytis leaf blight may be characterized as follows: lesion density and airborne inoculum were spatially randomly distributed during the first part (lag phase) of epidemics. Aggregation then occurred during a period when disease progress took place at a high rate. Towards the end of the epidemics, when the rate of disease increase tapered off, spatial patterns became random again. On the other hand, a managed epidemic of the disease, in addition to having low levels of disease, was associated with random distribution of both LD and ACC. These conclusions were derived from a set of field experiments on which a suite of analytical methods were applied; (i) Taylor's power law, which enables assessment of the relationship between disease (ACC) aggregation and disease (ACC) level; (ii) univariate SADIE analyses, which enabled quantitative characterization of aggregation levels (of LD or ACC) within a field; (iii) autocorrelation analyses, which enabled assessment of relationships between pathogen (ACC) levels in a given quadrat according to the distance with other quadrats in the field, and (iv) bi-variate SADIE analyses, which enabled assessment of relationships between disease and spore concentration, while accounting for the spatial structure of both variables (12). For Botrytis leaf blight of onion, this knowledge will provide support to a rational approach to disease management based on disease and airborne inoculum monitoring.

The two unmanaged epidemics studied differed considerably in final disease levels, but were similar for the duration of their initial lag phase, onset, and rate of disease progress (Fig. 1). Disease and inoculum progress were typical of airborne diseases with a logistic shape of disease progress curve. However, in 2004, the epidemic was characterized by a sudden increase in both lesion density and airborne inoculum concentration. Nevertheless, it was possible to detect structure in spatiotemporal pattern of both LD and ACC. For the managed epidemic, both airborne inoculum and LD remained low for most of the season and increased in August.

The adjustment of Taylor's law to the data over sampling dates showed that the level of aggregation usually increased with increasing means in the nonmanaged epidemics, while no aggregation was detected in the managed epidemics where disease intensity was low. In both years, the aggregation index measured by SADIE for LD suggested a random spatial pattern of disease early in the season, followed by an aggregated pattern in the second part of the epidemic. The pattern differed between the 2002 and the 2004 data sets. While the index of aggregation for

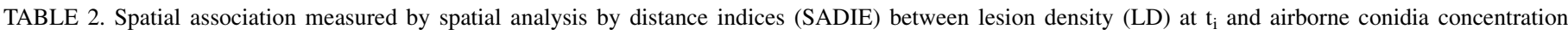
(ACC) at $\mathrm{t}_{\mathrm{i}}$, and between LD at $\mathrm{t}_{\mathrm{i}+1}$ and ACC at $\mathrm{t}_{\mathrm{i}}$ of Botrytis squamosa from unmanaged epidemics in 2002 and 2004

\begin{tabular}{|c|c|c|c|c|c|}
\hline \multicolumn{6}{|c|}{$\mathrm{I}_{\mathrm{t}}^{\mathrm{a}}(P$ value $)$} \\
\hline 2002 & $(\mathrm{LD}) \mathrm{t}_{\mathrm{i}}$ vs. $(\mathrm{ACC}) \mathrm{t}_{\mathrm{i}}$ & $(\mathrm{LD}) \mathrm{t}_{\mathrm{i}+1}$ vs. $(\mathrm{ACC}) \mathrm{t}_{\mathrm{i}}$ & 2004 & $(\mathrm{LD}) \mathrm{t}_{\mathrm{i}}$ vs. $(\mathrm{ACC}) \mathrm{t}_{\mathrm{i}}$ & $(\mathrm{LD}) \mathrm{t}_{\mathrm{i}+1}$ vs. $(\mathrm{ACC}) \mathrm{t}_{\mathrm{i}}$ \\
\hline 12 June & $0.19(0.138)$ & $0.70(0.001)$ & 10 June & $-0.10(0.727)$ & $-0.07(0.704)$ \\
\hline 20 June & $0.17(0.146)$ & $0.47(0.001)$ & 18 June & $0.42(0.001)$ & $0.42(0.001)$ \\
\hline 26 June & $0.46(0.006)$ & $0.57(0.001)$ & 23 June & $0.16(0.308)$ & $0.54(0.002)$ \\
\hline 3 July & $0.30(0.022)$ & $0.39(0.021)$ & 30 June & $0.35(0.011)$ & $0.37(0.008)$ \\
\hline 10 July & $0.19(0.105)$ & $0.86(0.001)$ & 7 July & $0.36(0.012)$ & $0.36(0.018)$ \\
\hline 17 July & $0.62(0.001)$ & $0.78(0.001)$ & 13 July & $0.33(0.012)$ & $0.33(0.023)$ \\
\hline 23 July & $0.55(0.001)$ & $0.66(0.003)$ & 21 July & $0.12(0.227)$ & $0.29(0.019)$ \\
\hline 1 August & $0.44(0.003)$ & $0.47(0.001)$ & 30 July & $0.10(0.250)$ & $0.22(0.048)$ \\
\hline 7 August & $0.14(0.125)$ & $0.07(0.318)$ & 4 August & $0.216(0.089)$ & \\
\hline 15 August & $0.17(0.201)$ & $0.33(0.018)$ & & & \\
\hline 21 August & $0.15(0.146)$ & & & & \\
\hline
\end{tabular}

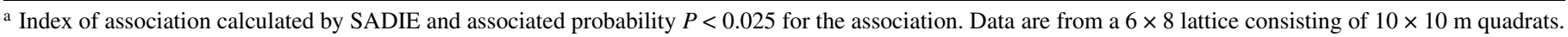


ACC was significantly $<1$ on most sampling dates in 2002 (no aggregation), it was significantly $>1$ on most sampling dates in 2004 , indicating some level of aggregation. For both years and for both variables, positive trends in partial autocorrelations were detected, mainly for a spatial lag of 1 , indicating that aggregation occurred within distances of about $10 \mathrm{~m}$. In 2002, partial autocorrelations were not significant for either variable in the first part of the epidemic while significant positive autocorrelations were detected as the epidemic progressed. In 2004, autocorrelations for LD were not significant for most sampling dates while it varied from one sampling to another for ACC. When Botrytis leaf blight was managed with fungicides, the indices of aggregation measured by SADIE were not significant except for ACC on the last sampling date of 2006 and no positive autocorrelation was found.

Based on these analyses, non-managed epidemics of Botrytis leaf blight may be characterized as follows: LD and airborne inoculum were spatially randomly distributed during a first part (lag phase) of epidemics; aggregation then occurred during a period when disease progress took place at a high rate; toward the end of epidemics, when the rate of disease increase decreased, spatial patterns became random again. Spatial autocorrelation analysis suggested that aggregation, when present, occurred over ranges of 10 to 25 meters only. Such pattern may be explained by epidemiological characteristics of Botrytis leaf blight. The main source of initial inoculum consists of conidia produced by overwintering sclerotia $(13,14)$. These sclerotia are produced the previous fall, and are more or less evenly distributed after soil cultivation, creating a nonaggregated distribution of sclerotia on the soil surface. The conidia produced by these sclerotia cause numerous initial lesions, which produce subsequent generations of conidia, which in turn cause secondary infections. At this exponential stage of the epidemics, infection efficiency depends mainly on leaf susceptibility and microclimate creating spatial variation in disease intensity and thus, local aggregation. As new generations of secondary inoculum are produced, the concentration of airborne conidia increases and spatial variation decreases. In their study on spatiotemporal development of cabbage downy mildew, Stein et al. (29) reported that spatial pattern of diseased plants varied over time and with increasing or decreasing disease incidence. They also observed a random pattern of diseased plants at the beginning of the epidemic (29).
Contrasting with aerially dispersed diseases, the spatial pattern of soilborne inoculum was studied for several diseases, including lettuce drop caused by Sclerotinia minor $(40,41)$. In this study, the degree of aggregation of sclerotia was initially low, and increased significantly during the cropping season under furrow irrigation, but not under surface drip irrigation. Similarly, Xiao et al. (42) studied the spatial pattern of microsclerotia of Verticillium dahliae, the causal agent of Verticillium wilt of cauliflower. Based on Lloyd's index of patchiness, they observed a low degree of aggregation in the pattern of microsclerotia. These two studies on the spatial pattern of sclerotia support our hypothesis that sclerotia of B. squamosa are randomly distributed, resulting in the lack of aggregation of both lesion density and airborne inoculum at the beginning of epidemics.

This study was conducted at a relatively small scale $(0.5$ and 1.6 ha) compared with typical onion fields in eastern Canada. The size of the experimental plot was limited by the possibility of using a large number of samplers on a large area. Nevertheless, it provided information on the spatial variability of disease intensity and of airborne inoculum. Boivin and Sauriol (5) studied the spatial distribution of Botrytis leaf blight in six commercial onion fields in southwestern Quebec, Canada, with weekly data collection from June to August, and individual LD per plant assessments over areas of 0.5 to 1 ha. This study led to conclude that Botrytis leaf blight lesions were spatially aggregated using Iwao's index. Another study (37) based on 50 assessments taken from 1983 to 1986 in 16 commercial onion fields in the Orange County, NY, yielded a similar conclusion. The present study did not enable detecting disease aggregation during the early phase of onion leaf blight epidemics. This difference in results may derive from differences in sampling schemes (here LD averaged over five plants were used and not individual plant LDs) and timing (this study considered epidemics from their onset).

It has been recently shown that airborne inoculum quantification, in combination with conventional disease assessment, is potentially useful in the management of Botrytis leaf blight of onion (9). This indicates that it should be possible to delay fungicide application until a threshold of airborne inoculum is reached, and so save up to 56 to $75 \%$ in the number of fungicide sprays without reduction in yield. This study reports good spatial correlations between LD at $t_{i+1}$ and airborne inoculum at $t_{i}$. In other words, measurement of airborne inoculum at $t_{i}$ could be a

TABLE 3. Spatial association measured by spatial analysis by distance indices (SADIE) between lesion density (LD) at $t_{\mathrm{i}}$ and airborne conidia concentration (ACC) at $t_{i}$, and between LD at $t_{i+1}$ and ACC at $t_{i}$ of Botrytis squamosa from managed epidemics in 2004 and 2006

\begin{tabular}{|c|c|c|c|c|c|}
\hline \multicolumn{6}{|c|}{$\mathrm{I}_{\mathrm{t}}^{\mathrm{a}}(P$ value $)$} \\
\hline 2004 & (LD) $\mathrm{t}_{\mathrm{i}}$ vs. $(\mathrm{ACC}) \mathrm{t}_{\mathrm{i}}$ & $(\mathrm{LD}) \mathrm{t}_{\mathrm{i}+1}$ vs. $(\mathrm{ACC}) \mathrm{t}_{\mathrm{i}}$ & 2006 & $(\mathrm{LD}) \mathrm{t}_{\mathrm{i}}$ vs. $(\mathrm{ACC}) \mathrm{t}_{\mathrm{i}}$ & $(\mathrm{LD}) \mathrm{t}_{\mathrm{i}+1}$ vs. $(\mathrm{ACC}) \mathrm{t}_{\mathrm{i}}$ \\
\hline 30 June & $0.66(0.001)$ & $0.78(0.001)$ & 28 June & $0.72(0.001)$ & $0.81(0.001)$ \\
\hline 8 July & $0.42(0.002)$ & $0.82(0.001)$ & 5 July & $0.56(0.004)$ & $0.79(0.001)$ \\
\hline 22 July & $0.43(0.003)$ & $0.81(0.001)$ & 19 July & $0.68(0.001)$ & $0.74(0.001)$ \\
\hline 29 July & $0.39(0.006)$ & $0.84(0.001)$ & 26 July & $0.59(0.003)$ & $0.81(0.001)$ \\
\hline 5 August & $0.54(0.002)$ & & 5 August & $0.49(0.003)$ & $0.71(0.001)$ \\
\hline
\end{tabular}

a Index of association calculated by SADIE and associated probability $P<0.025$ for the association. Data are from $5 \times 5$ lattice consisting of $25 \times 25 \mathrm{~m}$ quadrat.

TABLE 4. Mean airborne conidia concentration (ACC) and percentage of quadrats above the action threshold of 10 conidia per $\mathrm{m}^{3}$ of air

\begin{tabular}{|c|c|c|c|c|c|}
\hline 2004 & $\begin{array}{c}\text { Mean ACC } \\
\left(\text { conidia/ } / \mathrm{m}^{3}\right)^{\mathrm{a}}\end{array}$ & $\begin{array}{c}\% \text { Quadrats } \geq 10 \\
\text { conidia/ } \mathrm{m}^{3}\end{array}$ & 2006 & $\begin{array}{l}\text { Mean ACC } \\
\left(\text { conidia/ } \mathrm{m}^{3}\right)\end{array}$ & $\begin{array}{c}\% \text { Quadrats } \geq 10 \\
\text { conidia } / \mathrm{m}^{3}\end{array}$ \\
\hline 30 June & 1.3 & 0.0 & 28 June & 1.3 & 0.0 \\
\hline 8 July & 1.1 & 0.0 & 5 July & 2.6 & 0.0 \\
\hline 22 July & 0.5 & 0.0 & 19 July & 4.3 & 0.0 \\
\hline 29 July & 2.1 & 0.0 & 26 July & 18.8 & 96 \\
\hline 5 August & 5.6 & 0.0 & 05 August & 22.0 & 100 \\
\hline
\end{tabular}

a ACC, average of 25 samplers located in the center of each of the 25 quadrats $(5 \times 5$ lattice). 
good predictor of disease risk at $t_{i+1}$. This work indicates that LD and ACC were not aggregated during the early stage of epidemics, or when the disease is controlled with fungicides. The use of an airborne inoculum threshold as a tool for management of Botrytis leaf blight implies that monitoring can be achieved by only one or few samplers per field or farm. From a management standpoint, it is not necessary to know the exact amount of disease or airborne inoculum present, knowing whether disease exceeds the action threshold is sufficient for decision making. At the commercial site, almost all samplers (96 to 100\%) provided the same classification (i.e., as either above or below the threshold of 10 conidia per $\mathrm{m}^{3}$ of air) (Tables 3 and 4). An adequate monitoring of airborne inoculum for management of Botrytis leaf blight should therefore be achieved using only one or a few samplers per field. Considering that onion canopy is generally uniform, samplers could be positioned in the center of the field or in locations where microclimate is expected to influence Botrytis leaf blight.

\section{ACKNOWLEDGMENTS}

We thank D. Rolland, A. Lefebvre, M. Tremblay, J. Desteredjian, N. Surdek, and all the summer students and scouts from the PRISME consortium for their technical assistance and spore quantification. This work was financially supported by a Matching Investment Initiative between Agriculture and Agri-Food Canada, the PRISME Consortium and la Fédération des Producteurs Maraîchers du Québec.

\section{LITERATURE CITED}

1. Alderman, S. C., Biernbaum, J. A., Hoffhines, M., Timberlake, D. M., Welch, D. P., Lacy, M. L., and Barr, R. O. 1987. A simulation model of the spread of Botrytis leaf blight of onion and its effect on onion yields. Agric. Ecosyst. Environ. 19:55-70.

2. Alderman, S. C., and Lacy, M. L. 1983. Influence of dew period and temperature on infection of onion leaves by dry conidia of Botrytis squamosa. Phytopathology 73:1020-1023.

3. Aylor, D. E. 1998. The aerobiology of apple scab. Plant Dis. 82:838-849.

4. Aylor, D. E., and Kiyomoto, R. K. 1993. Relationship between aerial concentration of Venturia inaequalis ascospores and development of apple scab. Agric. For. Meteorol. 63:133-147.

5. Boivin, G., and Sauriol, P. 1984. Dispersion statistics and sequential sampling plan for leaf blight caused by Botrytis squamosa in onions. Phytopathology 74:1385-1387.

6. Bugiani, R., Govoni, P., Bottazzi, R., Giannico, P., and Montini, B. 1995. Monitoring airborne concentration of sporangia of Phytophthora infestans in relation to tomato late blight in Emilia Romagna, Italy. Aerobiologia 11:41-46.

7. Calderon, C., Ward, E., Freeman, J., and McCartney, A. 2001. Detection of airborne fungal spores sampled by rotating-arm and Hirst-type spore traps using polymerase chain reaction. J. Aerosol Sci. 33:283-296.

8. Campbell, C. L., and Madden, L. V. 1990. Introduction to Plant Disease Epidemiology. John Wiley and Sons, Toronto.

9. Carisse, O., McCartney, H. A., Gagnon, J. A., and Brodeur, L. 2005. Quantification of airborne inoculum as an aid in the management of Botrytis leaf blight of onion caused by Botrytis squamosa. Plant Dis. 89:726-733.

10. Charest, J., Dewdney, M., Paulitz, T., Philion, V., and Carisse, O. 2002. Spatial distribution of Venturia inaequalis airborne ascospores under commercial orchard conditions. Phytopathology 92:769-779.

11. Conseil des productions végétales du Québec. 1999. Légumes: Protection. Ministère de l'Agriculture, des pêcheries et de l'alimentation du Québec. Légumes agdex 250/1605.

12. Dale, M. R. T., Dixon, P., Fortin, M. J., Legendre, P., Myers, D. E., and Rosenberg, M. S. 2002. Conceptual and mathematical relationships among methods for spatial analysis. Ecography 25:558-577.

13. Ellerbrock, L. A., and Lorbeer, J. W. 1977. Sources of primary inoculum of Botrytis squamosa. Phytopathology 67:363-372.

14. Ellerbrock, L. A., and Lorbeer, J. W. 1977. Survival of sclerotia and conidia of Botrytis squamosa. Phytopathology 67:219-225.

15. Fitt, B. D. L., Gregory, P. H., Todd, A. D., McCartney, H. A., and Mac Donald, O. C. 1987. Spore dispersal and plant disease gradients; A comparison between two empirical models. J. Phytopathol. 118:227242 .
16. Gregory, P. H. 1945. The dispersion of air-borne spores. Transactions of the British Mycological Society 28:189-212.

17. Hughes, G., McRoberts, N., Madden, L. V., and Nelson, S. C. 1997. Validating mathematical models of plant disease progress in space and time. IMA J. Math. Appl. Med. Biol. 14:85-112.

18. Hughes, G., McRoberts, N., and Burnett, J. J. 1999. Decision-making and diagnosis in disease management. Plant Pathol. 48:147-153.

19. Lacy, M. L., and Pontius, G. A. 1983. Prediction of weather-mediated release of conidia of Botrytis squamosa from onion leaves in the fields. Phytopathology 73:670-676.

20. Madden, L. V. 2006. Botanical epidemiology: Some key advances and its continuing role in disease management. Special Issue: Plant Disease Epidemiology: Facing Challenges of the 21st Century. S. Savary, and M. Cooke, eds. Eur. J. Plant Pathol. 115:3-23.

21. McCartney, H. A., and Fitt, B. D. L. 1998. Dispersal of foliar fungal plant pathogens: Mechanisms, gradients and spatial pattern. Page 460 in: The Epidemiology of Plant Diseases. D. G. Jones, ed. Kluwer Academic Publishers, London.

22. Perry, J. N. 1995. Spatial analysis by distances indices. J. Anim. Ecol. 64:303-314.

23. Perry, J. N. 1998. Measures of spatial pattern for counts. Ecology 79:1008-1017.

24. Reynolds, K. M., and Madden, L. V. 1988. Analysis of epidemics using spatio-temporal autocorrelation. Phytopathology 78:240-246.

25. Savary, S., Castilla, N. P., and Willocquet, L. 2001. Analysis of the spatiotemporal structure of rice sheath blight in a farmer's field. Plant Pathol. 50:53-68.

26. Scherm, H, Ngugi, H. K., and Ojiambo, P. S. 2006. Trends in theoretical plant epidemiology. Special Issue: Plant Disease Epidemiology: Facing Challenges of the 21 st Century. S. Savary, and M. Cooke, eds. Eur. J. Plant Pathol. 115:3-23.

27. Schmale, D. G., Shah, D. A., and Bergstrom, G. C. 2005. Spatial patterns of viable spore deposition of Gibberella zeae in wheat fields. Phytopathology 95:472-479.

28. Shoemaker, P. B., and Lorbeer, J. W. 1977. Timing initial fungicide application to control Botrytis leaf blight epidemics on onions. Phytopathology 67:409-414

29. Stein, A., Kocks, C. G., Zadoks, J. C., Frinking, H. D., Ruissen, M. A., and Myers, D. E. 1994. A geostatistical analysis of the spatio-temporal development of downy mildew epidemics in cabbage. Phytopathology 84:1227-1239.

30. Sutton, J. C., James, T. D. W., and Rowell, P. M. 1983. Relation of weather and host factors to an epidemic of Botrytis leaf blight in onions. Can. J. Plant Pathol. 5:256-265.

31. Sutton, J. C., James, T. D. W., and Rowell, P. M., 1986. BOTCAST: A forecasting system to time the initial fungicide sprays for managing Botrytis leaf blight of onions. Agric. Ecosyst. Environ. 18:123-143.

32. Sutton, J. C., Swanton, C. J., and Gillespie, T. J. 1978. Relation of weather variables and host factors to incidence of airborne spores of Botrytis squamosa. Can. J. Bot. 56:2460-2469.

33. Taylor, L. R. 1961. Aggregation, variance and the mean. Nature 189:732-735.

34. Van der Plank, J. E. 1963. Page 344 in: Plant Diseases: Epidemics and Control. Academic Press, New York.

35. Viennot-Bourgin, G., 1952. Sur la présence en France de Botrytis squamosa, parasite de l'oignon. Rev. Pathol. Vég. Entomol. Agric. 31:82.

36. Vincelli, P. C., and Lorbeer, J. W. 1989. BLIGHT-ALERT: A weatherbased predictive system for timing fungicide applications on onion before infection periods of Botrytis squamosa. Phytopathology 79:493-498.

37. Vincelli, P. C., and Lorbeer, J. W. 1987. Sequential sampling plan for timing initial fungicide application to control Botrytis leaf blight of onion. Phytopathology 77:1301-1303.

38. Vincelli, P. C., and Lorbeer, J. W. 1988. Relationship of precipitation probability to infection potential of Botrytis squamosa on onion. Phytopathology 78:1078-1982.

39. Waggoner, P. E., and Aylor, D. E. 2000. Epidemiology: A science of patterns. Annu. Rev. Phytopathol. 38:71-94

40. Wu, B. M., and Subbarao, K. V. 2003. Effect of irrigation and tillage on temporal and spatial dynamics of Sclerotinia minor sclerotia and lettuce drop incidence. Phytopathology 93:1572-1580.

41. Wu, B. M., van Bruggen, A. H. C., Subbarao, K. V., and Pennings, G. G. H. 2001. Spatial analysis of lettuce downy mildew using geostastistics and geographic information systems. Phytopathology 91:134-142.

42. Xiao, C. L., Hao, J. J., and Subbarao, K. V. 1997. Spatial pattern of microsclerotia of Verticillium dahliae in soil and Verticillium wilt of cauliflower. Phytopathology 87:325-331.

43. Zadoks, J. C., and Schein, R. D. 1979. Page 427 in: Epidemiology and Plant Disease Management. Oxford University Press, New York. 